\title{
Characterization of Guinier-Preston Zones in Mg-Gd-Zn Alloys by Using Transmission Electron Microscopy
}

\author{
Akira YASUHARA*, Kaichi SAITO**, Masahiko NISHIJIMA***, and Kenji HIRAGA*** \\ * EM Application Group, EM Business Unit, JEOL Ltd., Tokyo 196-8558, Japan \\ ** Department of Materials Science and Engineering, Akita University, Akita 010-8502, Japan \\ *** Institute for Materials Research, Tohoku University, Sendai 980-8577, Japan
}

The investigation of Mg-based alloys become increasingly activated because of their attractive features such as quite low density and high strength mechanical properties, aiming at the development of a newly structural material. Especially, Mg-Gd-Zn alloys have been found to reveal remarkable age-hardening effects. It is also interesting that these materials generate a wide variety of precipitations ( $\beta^{\prime}-,, \beta 1-$,LSPO[1] and Guinier-Preston zones (GP-Zones) [2]) through the aging treatment. According to a recent study about Mg-Gd-Zn alloys, the microstructures of precipitations significantly change depending on the composition of $\mathrm{Gd} / \mathrm{Zn}$ and thermal history. Besides, when a composition ratio of $\mathrm{Gd}$ to $\mathrm{Zn}$ is between 1 and 1.5, GP-zone precipitation is preferentially generated. And a rather complex texture appears with an advance of aging treatment.

In this study, we focus on the GP-zone in Mg-Gd-Zn alloys and characterize their growth process. And we report results on the structural features of the GP-zones using a transmission electron microscope.

Alloys with nominal compositions of $\mathrm{Mg}_{98} \mathrm{Gd}_{1.0} \mathrm{Zn}_{1.0}, \quad \mathrm{Mg}_{99} \mathrm{Gd}_{0.5} \mathrm{Zn}_{0.5} \quad(\mathrm{Gd} / \mathrm{Zn}=1)$, and $\mathrm{Mg}_{97.5} \mathrm{Gd}_{1.5} \mathrm{Zn}_{1.0}(\mathrm{Gd} / \mathrm{Zn}=1.5)$ were prepared by melt-mixing in carbon crucibles using an induction heating system under Ar gas atmosphere. The purities of material metals were $99.9 \%(\mathrm{Mg}$ and $\mathrm{Gd})$ and $99.95 \%(\mathrm{Zn})$. The alloys were annealed at $520^{\circ} \mathrm{C}$ for $2 \mathrm{hrs}$ and aged at $200 \mathrm{C}$ for various periods of time, and they were finally quenched in water. Thin specimens for a TEM observation were prepared by ion-milling method. STEM HAADF images were acquired by a field emission electron microscope, JEM-2100F (TEM / STEM).

Selected area electron diffraction patterns of $\mathrm{Mg}_{97.5} \mathrm{Gd}_{1.5} \mathrm{Zn}_{0.5}$ alloy aged at $200^{\circ} \mathrm{C}$ for 100 hours are shown in Figs...1(a) and 1(b). The incident directions for these electron diffraction patterns are [001] and [1-10] of the Mg matrix (which has a Hexagonal Closed Packed (HCP) structure). These patterns include the reflections due to GP-zones. In fact, they show that extra spots corresponding to 1/3 1/3 0-type reflections in Fig. 1(a) and streak reflections in Fig.1 (b), both of which are originated from the GP-zones present perpendicular to the c-axis of the Mg matrix.

Figure 2 shows a STEM HAADF image observed from the direction perpendicular to c-axis of $\mathrm{Mg}_{97.5} \mathrm{Gd}_{1.5} \mathrm{Zn}_{0.5}$ alloy, which was annealed at $200^{\circ} \mathrm{C}$ for 100 hours. Sharp bright lines (ranged between 50 and $100 \mathrm{~nm}$ in length) are observed. These lines correspond to the GP-Zones being parallel to the c-plane of the $\mathrm{Mg}$ matrix.

In Fig.3, high-resolution STEM HAADF images of the GP-zone in the Mg-Gd-Zn alloys(taken by the incident beam directions with [1-10] and [100], respectively) are shown. These results indicate that the GP-zones are arranged high-integrity with the HCP-Mg matrix and composed of such a heavy elements as Gd and/or Zn. From our other results, it is indicated that the GP-Zones in $\mathrm{Mg}-\mathrm{Gd}-\mathrm{Zn}$ alloys change their microstructures with an advance of aging in the following way; Wavy GP-Zone $\rightarrow$ Planar GP-Zone $\rightarrow$ multi-layered GP-Zones $(\rightarrow$ Stacking fault)[3]. 


\section{References:}

[1] M. Yamasaki et al., Acta Mater. 55 (2007) p.6798

[2] M. Nishijima et. al., Mater. Trans. 49 (2008) p.227A.

[3] K. Saito et al., J. Alloy and Comp. 509 (2011) p2031
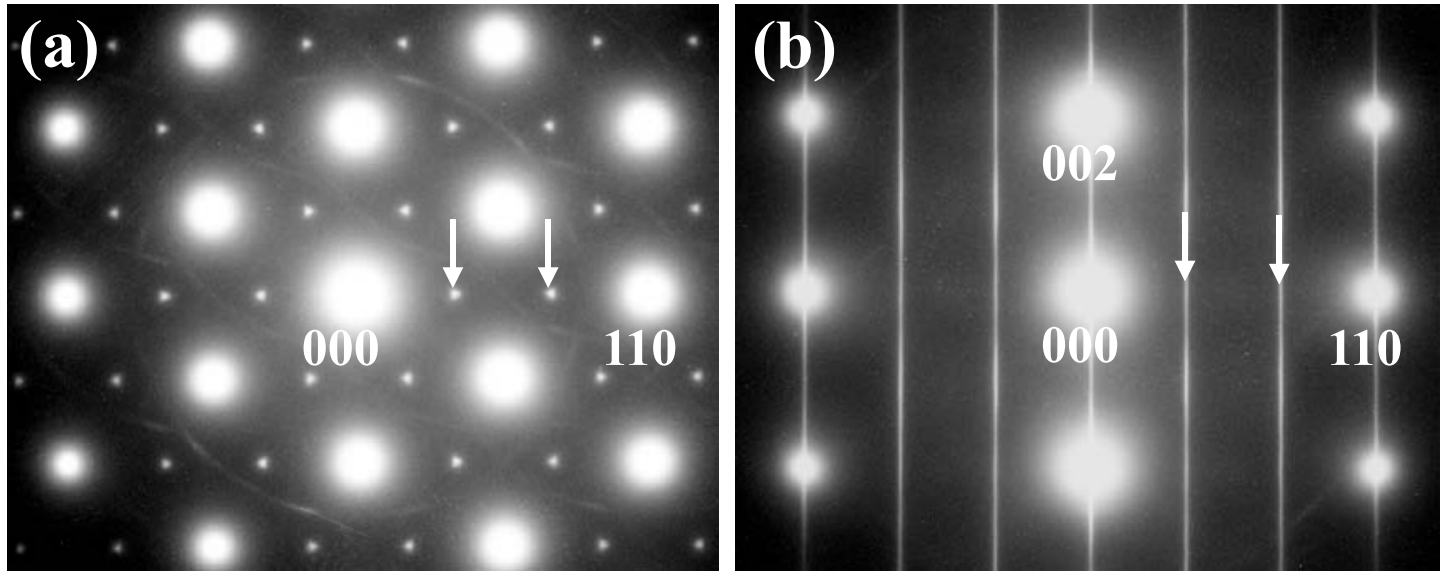

Fig.1 Selected Area Electron Diffraction Pattern of $\mathrm{Mg}_{98} \mathrm{Gd}_{1.5} \mathrm{Zn}_{1}$ alloy annealed at $200^{\circ} \mathrm{C}$ for 100 hours. Each diffraction pattern (a)and (b)was recorded with the incident beam parallel to a [001] and [1-10] direction of the Mg matrix. Extra spots and steak reflections indicated by[white arrows were both originated from GP-zone.

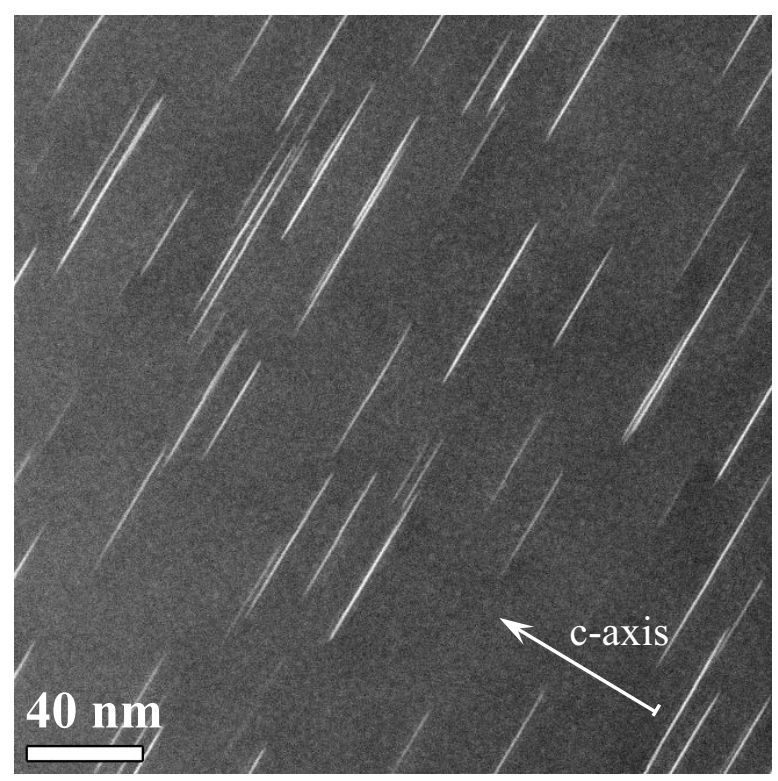

Fig.2 STEM HAADF image of $\mathrm{Mg}_{98} \mathrm{Gd}_{1.5} \mathrm{Zn}_{1}$ alloy annealed at $200^{\circ} \mathrm{C}$ for 100 hours, taken with the incident beam perpendicular to a c-axis of the $\mathrm{Mg}$ matrix.
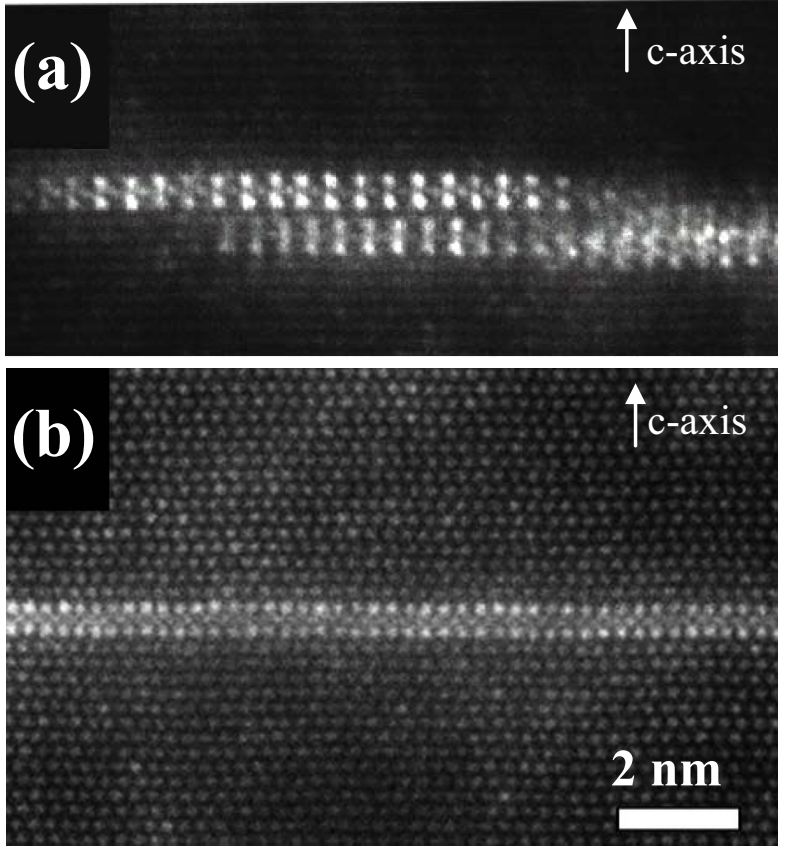

Fig.3 High-resolution STEM HAADF images of $\mathrm{Mg}-\mathrm{Gd}-\mathrm{Zn}$ alloys, taken with a incident beam parallel to the [1-10] direction (a) and [100] direction (b) of the $\mathrm{Mg}$ matrix. 